\title{
Retention of discrimination learning sets by cats'
}

\section{J. M. WARREN, The Pennsylvania State University, University Park, Pa. 16802}

Experimental and control groups of five and four cats, respectively, were trained to criterion on 96 form-discrimination problems. The experimental group received 100 days of training on double alternation, and the control group went untested, over an interval of 7 months. Both groups were then tested on 32 new form discriminations and manifested equivalent retention of the discrimination learning set. The results for individual Ss indicate that learning set performance in cats is unaffected by long interruptions in testing or by interpolated training on an insoluble potentially conflicting task, unless $S$ learns a response strategy which is antagonistic to efficient visual-discrimination performance.

Interpolated training on insoluble learning problems disrupts the retention of position reversal sets by rats (Dalrymple \& Stretch, 1966) and the retention of object discrimination learning sets by squirrel monkeys (Rumbaugh \& Prim, 1964). The purpose of the present experiment was to determine the effect of interpolated training on an insoluble double-alternation task upon the retention of discrimination learning sets by cats.

\section{SUBJECTS}

The Ss were nine experimentally naive adult cats, four mongrels and five Siamese, which were trained to manipulate objects and to take meat from the test tray of the Wisconsin General Test Apparatus (WGTA) for at least 8 days before testing on discrimination problems.

\section{APPARATUS}

All of the testing was carried out in the WGTA (Harlow, 1949). The stimuli were 30

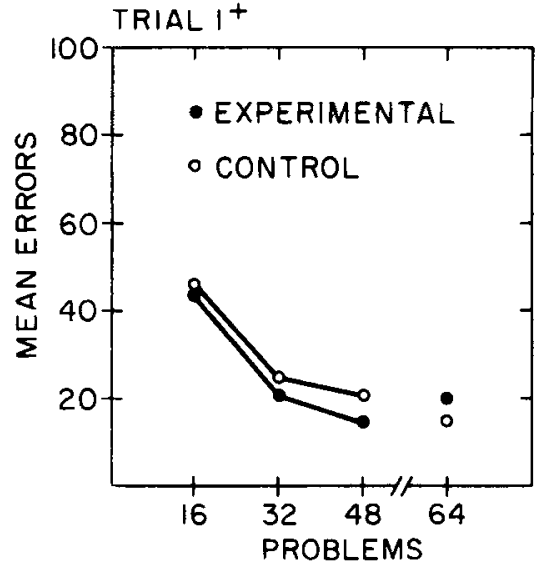

black geometrical figures made of 1 -in. lumber, with surface areas of $80 \mathrm{sq} \mathrm{cm}$, and presented on a white test tray containing two food wells spaced 12 in. apart. PROCEDURE

Learning Set Acquisition

The trial setting procedures used for testing cats on object discriminations in the WGTA have been described in detail by Warren \& Baron (1956). The cats were trained, with 50 noncorrection trials a day, to a criterion of 10 consecutive correct responses, on 96 discriminations between unique pairs of the 30 stimulus figures. Each cat learned 24 discrimination problems under four different conditions. On half of the problems, $S$ was rewarded for choices of its initially preferred stimulus (Trial $1+$ problems), and on half the problems, it was rewarded for choices of the initially nonpreferred stimulus (Trial 1 - problems) in half the problems within each of these classes, the stimuli were presented in the vertical plane, with the figures supported by concealed braces, and in the remaining problems the stimuli were presented in the horizontal plane, lying upon the surface of the test tray. Subgroups of two or three cats learned each discrimination under all four conditions defined in respect to Trial 1 reinforcement (+ or - ) and orientation of the figures (horizontal or vertical), and every cat learned one problem under all four conditions over each block of four discriminations. The assignments of $\mathrm{Ss}$ to conditions by means of Latin squares rendered preference and stimulus display conditions orthogonal to particular pairs of figures.

\section{Double Alternation Training}

The Ss were divided into experimental and control groups of five and four cats,

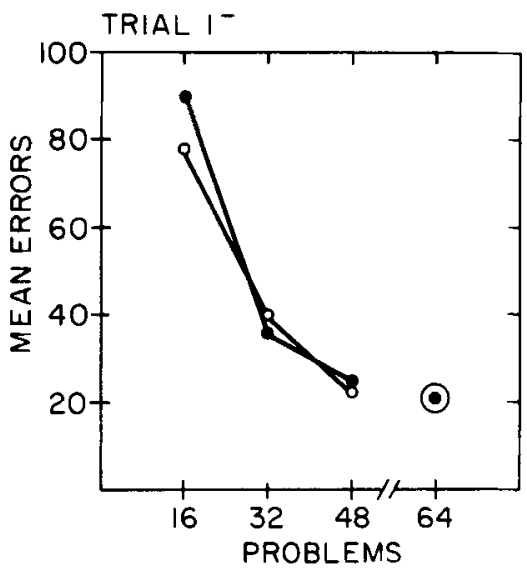

respectively, matched in terms of their error scores on the last 32 learning set problems. Over a period of 7 months, the experimental animals were given 100 days of training on double alternation; they were tested on four double-alternation sequences of eight responses (RRLLRRLL) with a rerun correction procedure in each test session, under conditions that were otherwise identical with those described by Stewart \& Warren (1957). The control Ss went untested for 7 months at this stage of the experiment.

Retention of Learning Set

All of the cats were trained to criterion on 32 new form-discrimination problems under the conditions that obtained in the acquisition series.

Deprivation and reinforcement conditions remained constant throughout the experiment. The cats were tested under low (12 to $23 \mathrm{~h}$ ) levels of deprivation and reinforced for correct responses with small $(1 / 4-i n$.$) cubes of pork kidney, a highly$ preferred food for cats.

\section{Experimental Design}

The analysis of variance on errors to criterion in the acquisition series of discrimination problems was a factorial with stimuli, Trial 1 reinforcement, blocks of 32 problems, between groups, and within groups as main effects. The analysis of the retention scores was identical except for the omission of problem blocks as a source of variance.

\section{RESULTS}

The mean number of errors to criterion for the experimental and control groups on successive blocks of 16 problems under the Trial $1+$ and - conditions is shown in Fig. I; the breaks in the abscissae indicate the interval between the acquisition and retention series of problems. It is immediately apparent that the interruption in discrimination testing had essentially no effect on discrimination learning performance by the experimental or control groups of cats.

The analysis of variance on the retention scores indicates that problem blocks $(F=24, \quad \mathrm{df}=2 / 54, \quad \mathrm{p}<.001), \quad$ Trial 1 reinforcement $(F=13, d f=1 / 54, p<.001)$ and the interaction, Problem Blocks by Trial 1 Reinforcement $(\mathrm{F}=3.40, \mathrm{df}=2 / 54$, $\mathrm{p}<.05)$ were the only significant sources of variation; $t$ tests for related measures indicate that the cats' performance on the Trial 1+ and Trial 1- problems differed significantly on the first two, but not on the last block of acquisition problems. None of the main effects or interaction terms was significant in the analysis of the retention error scores.

Fig. 1. Learning-set performance by experimental and control groups of cats. 

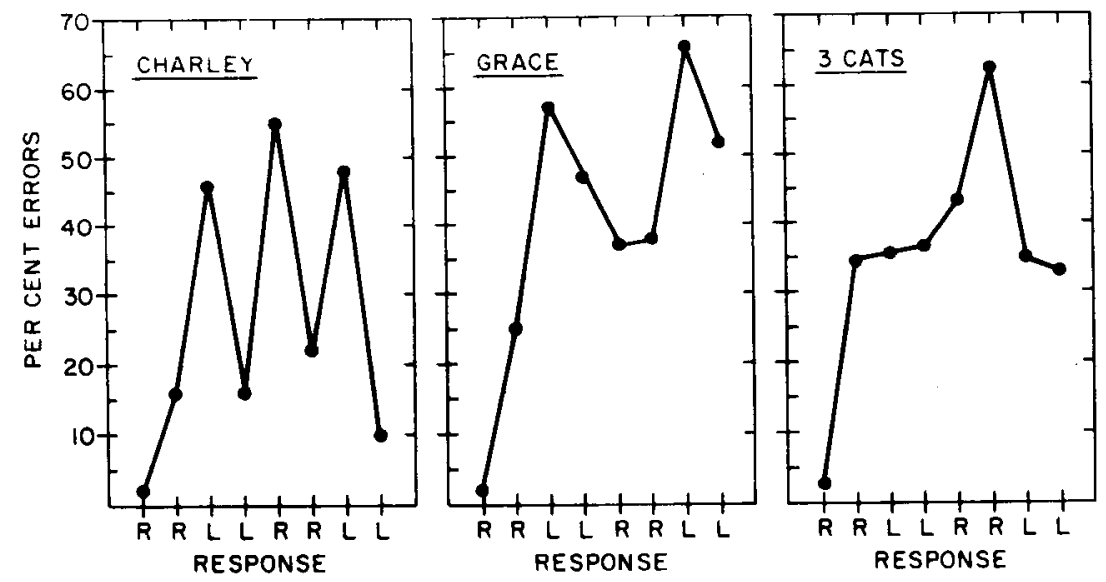

None of the experimental Ss approached solution of the double-alternation problem. The mean percentage of correct responses on the last 25 days of training on double alternation was 66 ; individual scores ranged from $60 \%$ to $74 \%$ correct responses. Analysis of the cats' performances revealed, however, that the five Ss manifested three different sorts of response strategies on double alternation. These are illustrated in Fig. 2 which shows the percentage of errors made on each response in the double-alternation sequence over the last 100 sequences (25 days). Cat Charley manifested a strong tendency to perseverate after reinforcement and to shift after nonreinforcement. Grace developed a significant right-position bias. The remaining three cats apparently learned that the right position was rewarded at the start of each sequence and little more than this since they responded at or near chance on later trials in the sequence. Charley, the cat that developed a "win-stay, lose-shift with respect to position" strategy, was exceptional in his retest performance in discrimination learning; he made more than twice as many errors on the problems that followed double-alternation training than he had before the interpolated training (668 errors on Problems 97-128 vs 328 on Problems 65-96).

\section{DISCUSSION}

The group results indicate that prolonged and unsuccessful training on an insoluble problem does not interfere with the retention of discrimination-learning sets by cats. It is clear that prolonged training on an insoluble task is neither a necessary nor a sufficient condition for disruption of visual-discrimination learning sets in cats.

One cat, Charley, developed a relatively stable stereotyped pattern of responding on double alternation. This $S$ was the only animal which was markedly deficient in retest performance on visual-discrimination problems, suggesting that the acquisition of specific sequential patterns of response that conflict with the responses essential for efficient learning-set performance is a necessary condition for impairment of the retention of learning sets in cats. The fact that a second cat, Grace, developed a strong position bias but was not subsequently impaired in learning-set performance implies that the development of response habits incompatible with efficient visual discrimination is not sufficient to impair retention of visual discrimination-learning sets. This interpretation makes it possible to resolve the otherwise puzzling paradox posed by Warren \& Sinha's (1959) observation that interpolated training on a soluble double-altemation problem depresses the retention of a visual discrimination learning set by rhesus monkeys. The monkeys, like the exceptional cat Charley, learned to make stereotyped sequences of positional responses in training on double altemation and thus were subject to conflict between

\section{RAY OVER, Dalhousie University, Halifax, Nova Scotia, Canada}

Four pigeons were trained to discriminate between mirror-image oblique lines and between horizontal and vertical lines. On each trial, a response on the center key displayed one of the discriminative stimuli, and reinforcement was gained by a response on the appropriate side key. Choice reaction times did not differ for the two sets of
Fig. 2. Intrasequential distribution of errors on eight-response double-alternation sequences.

antagonistic response tendencies when retested on visual discriminations.

It should be noted that the results obtained from the control group of cats in this experiment indicate that the retention of discrimination-learning sets is as little affected by long interruptions in testing as seems to be the case with monkeys (Miles, 1965).

\section{REFERENCES}

DALRYMPLE, S. D., \& STRETCH, R. Disruption of a position-reversal learning set in the rat. Quarterly Journal of Experimental Psychology, $1966,18,250-253$.

HARLOW, H. F. The formation of learning sets. Psychological Review, 1949, 56, 51-65.

MILES, R. C. Discrimination-learning sets. In A. M. Schrier, H. F. Harlow, and F. Stollnitz (Eds.), Behavior of nonhuman primates: Modern research trends. Vol. 1. New York: Academic Press, 1965. Pp. 51-95.

RUMBAUGH, D. M., \& PRIM, M. M. Temporary interference of insolvable discrimination reversal training upon learning set in the squirrel monkey. Journal of Comparative \& Physiological Psychology, 1964, 57, 302-304. STEWART, C. N., \& WARREN, J.M. The behavior of cats on the double-alternation problem. Journal of Comparative \& Physiological Psychology, 1957, 50, 26-28.

WARREN, J. M., \& BARON, A. The formation of learning sets by cats. Journal of Comparative \& Physiological Psychology, 1956, 49, 227-231.

WARREN, J. M., \& SINHA, M. M. Interactions between learning sets in monkeys. Journal of Genetic Psychology, 1959, 95, 19-25.

$$
\text { NOTE }
$$

1 . This research was supported by Grant MH-04726 from the National Institute of Mental Health, United States Public Health Service.

\section{Reaction time analysis of discrimination of direction of line by the pigeon ${ }^{1}$}

figures These results are consistent with trials-to-criterion measures of the discrimination of direction of line by the pigeon.

Shape discrimination by animals is studied by presenting two figures, either simultaneously or successively, and rewarding responses specific to one shape but not to the other. An animal's ability to 